\title{
Effects of chronic systemic insulin delivery on insulin action in dogs
}

\author{
M.Homan, C. P. Nicholson, H. Katz, J. Perkins, M. Haymond, M.Jensen, P. Butler and R. Rizza \\ Endocrine Research Unit, Departments of Medicine and Surgery, Mayo Clinic, Rochester, Minnesota, USA
}

\begin{abstract}
Summary. The metabolic consequences of the prolonged systemic insulin delivery associated with human pancreas transplantation have not been precisely defined. To determine if systemic insulin delivery in the absence of immunosuppressive agents results in alterations in hepatic or extrahepatic insulin action, three groups of dogs were studied 2 months after either a sham operation or after their pancreatic venous drainage was severed and anastomosed to the inferior vena cava or portal vein (sham, peripheral and portal groups, respectively). The pattern of venous drainage was documented by measuring vena cava and portal insulin concentrations before and after glucose injection. Systemic insulin concentrations were higher $(p<0.05)$ in the peripheral group than in the portal group both following a 14-h fast and after intravenous glucose. During a hyperinsulinaemic euglycaemic clamp $\left(1 \mathrm{mU} \cdot \mathrm{kg}^{-1} \cdot \mathrm{min}^{-1}\right)$, glucose utilization (measured using $\left[6^{3} \mathrm{H}\right]$ glucose) was slightly lower $(p=0.07)$ in the peripheral
\end{abstract}

than in the portal group. Hepatic glucose release was equal in all groups. Carbon dioxide incorporation into glucose (an estimate of gluconeogenesis) was higher in the portal than peripheral group in the fasted state but not during insulin infusion. Plasma concentrations and flux rates of fatty acids and amino acids did not differ between groups. We conclude that chronic systemic insulin delivery results in a) systemic but not portal hyperinsulinaemia, b) a minimal impairment in insulin-stimulated glucose uptake, without altering insulin-induced suppression of hepatic glucose release, and c) no effect on fatty acid or amino acid turnover. Although chronic systemic insulin delivery appears to have a minimal effect on insulin action, it remains to be determined whether it has other deleterious effects such as enhancing atherogenesis.

Key words: Systemic insulin, hyperinsulinaemia, insulin action.
One of the goals of pancreas transplantation is to prevent the acute and chronic complications of diabetes mellitus. This may require normalization of metabolism as well as concentrations of glucose, non-esterified fatty acids (NEFA) and amino acids. As currently performed, human pancreas transplantation markedly improves glucose tolerance but does so at the price of systemic hyperinsulinaemia [1-4]. The increased circulating insulin concentrations are believed to be due, at least in part, to drainage of the pancreas venous effluent into the systemic rather than the portal venous circulation [5]. While the long-term effects of hyperinsulinaemia remain uncertain, both in vitro $[6-8]$ and in vivo $[9,10]$ experiments suggest that increased insulin concentrations can cause insulin resistance. If this is so, it may not only impair substrate metabolism but may also accelerate graft failure by increasing insulin requirements. Anastomosis of a pancreatic graft to the inferior vena cava also abolishes the portal-peripheral venous insulin gradient [11]. Therefore, the liver may be exposed to lower rather than higher insulin concentrations. Thus, it is possible that chronic systemic insulin de- livery may via "upregulation" result in increased hepatic and via "downregulation" decreased extrahepatic insulin action.

We have previously reported that anastomosis of the pancreaticoduodenal vein to the inferior vena cava in dogs results in chronic systemic hyperinsulinaemia without altering fasting glucose concentrations or postprandial carbohydrate tolerance [12]. In the present experiments, we have used the same model to directly test the hypothesis that systemic insulin delivery impairs the ability of insulin to modulate carbohydrate, protein and NEFA metabolism.

\section{Materials and methods}

Animals and surgery

After approval of the protocol by the Mayo Animal Care and Use Committee, 33 healthy mongrel dogs ( 30 females, 3 males) weighing between 16 and $25 \mathrm{~kg}$ were anaesthetized with methohexital 
(12 $\mathrm{mg} / \mathrm{kg}$ body weight i. v.) following an overnight fast. The dogs were randomly assigned to one of three surgical procedures, the details of which have been previously described [13]. Briefly, the entire venous drainage of the pancreas was transected and/or ligated except for the superior pancreaticoduodenal vein (SPDV), which was mobilized, transected from the portal vein, and either anastomosed to the inferior vena cava (peripheral group) or reanastomosed to the portal vein (portal group). Since this operation necessitates an approximate $25-40 \%$ pancreatectomy, we compared the results in the portal group to those in sham-operated dogs who underwent only a midline abdominal incision with removal of the intra-abdominal fat pad. Weight and gender distribution was comparable in the peripheral $(19.4 \pm 0.8 \mathrm{~kg}, 7$ female, 1 male $)$, portal $(19.5 \pm 1.0 \mathrm{~kg}, 7$ female, 1 male), and sham groups ( $22.0 \pm 0.7 \mathrm{~kg}, 8$ female, 1 male) .

After post-operative recovery, animals were fed once daily with $1400 \mathrm{~g}$ of standard dog chow (Country Prime, Mankato, Minn., USA) and allowed water ad libitum. Between 7 and 9 weeks postoperatively, the dogs were again anaesthetized as above and a Silastic catheter (no.602-205, Dow Corning, Midland, Mich., USA) was implanted in a femoral artery. The catheter was flushed with $2 \mathrm{ml}$ heparinized $(50 \mathrm{U} / \mathrm{ml}) \mathrm{NaCl}(154 \mathrm{mmol} / \mathrm{l})$, ligated, and sutured subcutaneously. Hyperinsulinaemic clamp studies were performed 6 to 14 days later ( 8 to 10 weeks after initial surgery).

\section{Experimental procedures}

At the time of the hyperinsulinaemic clamp studies, all animals had haemoglobin levels of $\geq 10.5$, leucocyte counts $\leq 14.5$, stable weight, normal stools, good appetites and appeared in healthy condition. Food was removed from cages $24 \mathrm{~h}$ prior to the study; water was continued ad libitum until the morning of study. On the morning of the study, the femoral artery catheter was retrieved under local anaesthesia ( $2 \%$ lidocaine [2-3 ml]; Abbott, North Chicago, Ill., USA) and was used for blood collection. Central venous access was obtained with a 16 gauge 24" Intracath (Deseret Medical, Sandy, Utah, USA) which was inserted in a saphenous vein on the morning of the study for infusions of hormones, glucose and isotopes.

A primed $(3.1 \mu \mathrm{Ci})$ continuous $(0.03 \mu \mathrm{Ci} / \mathrm{min})$ infusion of [6- $\left.{ }^{3} \mathrm{H}\right]$ glucose, a primed $(100 \mu \mathrm{Ci})$ continuous $(1 \mu \mathrm{Ci} / \mathrm{min})$ infusion of $\mathrm{H}^{14} \mathrm{CO}_{3}$ (both from DuPont-NEN, Boston, Mass., USA), and a primed $(1.1 \mathrm{mg} / \mathrm{kg})$ continuous $\left(0.01 \mathrm{mg} \cdot \mathrm{kg}^{-1} \cdot \mathrm{min}^{-1}\right)$ infusion of L- $\left[5,5,5-{ }^{2} \mathrm{H}_{3}\right]$ leucine (99\% mol \% enrichment; MSD, Quebec, Canada) were started $180 \mathrm{~min}$ prior to starting hormone infusions. [9, $10^{3} \mathrm{H}$ ] palmitate (Amersham, Arlington Heights, Ill., USA) was infused $(0.24 \mu \mathrm{Ci} / \mathrm{min})$ for a $60-\mathrm{min}$ period immediately prior to starting hormone infusions.

Infusions of insulin $\left(1.0 \mathrm{mU} \cdot \mathrm{kg}^{-1} \cdot \mathrm{min}^{-1}\right.$; Humulin R, Lilly, Indianapolis, Ind., USA), glucagon $\left(0.42 \mathrm{ng} \cdot \mathrm{kg}^{-1} \cdot \mathrm{min}^{-1}\right.$; Lilly) and somatostatin (200 $\mathrm{ng} \cdot \mathrm{kg}^{-1} \cdot \mathrm{min}^{-1}$; Serono, Randolph, Mass., USA) were started simultaneously at time 0 and continued for $180 \mathrm{~min}$. All hormone solutions were diluted in $154 \mathrm{mmol} / 1 \mathrm{NaCl}$ and contained a final concentration of $1 \%$ albumin ( $25 \%$ Human Albumin; Miles, Elkhart, Ind., USA). Arterial plasma glucose was measured every $5 \mathrm{~min}$ (YSI, Yellow Springs, Ohio, USA) during insulin infusion, and the rate of a glucose infusion (20\% Dextrose; Baxter, Deerfield, Ill., USA; or $30 \%$ Dextrose; Travenol, Deerfield, Ill., USA) was varied using a programmable infusion pump (Harvard, South Natick, Mass., USA) to maintain euglycaemia. Exogenous glucose was labelled with $\left[6-{ }^{3} \mathrm{H}\right]$ glucose resulting in an exogenous glucose specific activity $(7.78 \mu \mathrm{Ci} \times$ body weight $(\mathrm{kg}) / \mathrm{g}$ glucose $)$ calculated to maintain plasma $\left[6-{ }^{3} \mathrm{H}\right]$ glucose specific activity constant during the clamp period.

Arterial blood was also sampled for measurement of insulin [14], and glucagon [15] at regular intervals. Breath was collected via a tight-fitting rubber glove placed over the animal's snout into $2 \mathrm{ml}$ of $0.5 \mathrm{mmol} / 1$ Hyamine (Packard, Downer's Grove, Ill., USA). Optifluor $\left(10 \mathrm{ml}\right.$; Packard) was added and ${ }^{14} \mathrm{CO}_{2}$ specific activity was measured as previously described [16]. Within 1 week of the study, the dogs were anaesthetized as above and underwent abdominal exploration. The SPDV was isolated and flow was documented using a flow probe (Transonic Systems, Ithaca, N.Y., USA). To verify that pancreatic venous drainage of insulin was as intended, insulin concentrations were measured in simultaneous venous samples obtained from three sites: 1) portal vein (PV), 2) proximal inferior vena cava (P-IVC), and 3) distal inferior vena cava (D-IVC) at baseline and 5 and 10 min after peripheral venous injection of $10 \mathrm{~g}$ i.v. glucose. The tip of the portal vein catheter was advanced to the porta hepatis. The P-IVC catheter was placed in the vena cava at a location that would be cephalad to the site of anastomosis of the pancreatoduodenal vein in the peripheral group. The D-IVC catheter was placed in the vena cava at a location that would be caudad to the site of anastomosis of the pancreatoduodenal vein. Peripheral drainage was defined prospectively as PIV $>$ DIV and PV $=$ DIV insulin in at least 2 of 3 timepoints, and portal drainage was defined as PV $>P I V$ and PIV $=$ DIV insulin in at least 2 of 3 timepoints. Five dogs in the original peripheral group and three dogs in the original portal group did not meet these criteria and were therefore excluded from further analysis leaving $25 \mathrm{dogs}$ for final analysis (nine sham, eight portal and eight peripheral).

\section{Analysis}

Specific activity of $\left[6-{ }^{3} \mathrm{H}\right]$ - and $\left[{ }^{14} \mathrm{C}\right]$ glucose were measured as previously described [17]. Loss of $\left[9,10-{ }^{3} \mathrm{H}\right]$ palmitate during deproteinization and ion exchange chromatography was $>99.9 \%$. [9, $\left.10-{ }^{3} \mathrm{H}\right]$ palmitate specific activity was measured by HPLC using $\left[{ }^{2} \mathrm{H}_{31}\right]$ palmitate internal standard [18]. The relative purity of the $\left[{ }^{3} \mathrm{H}\right]$ palmitate tracer was determined using $\left[1-{ }^{14} \mathrm{C}\right]$ palmitate as an internal standard [19]. L-[5, 5, 5- $\left.{ }^{2} \mathrm{H}_{3}\right]$ leucine and ketoisocaproic acid enrichment were determined by gas-chromatography mass spectrometry [20].

\section{Calculations}

Rates of glucose and palmitate turnover were calculated using the steady-state equations of Steele et al. [21]. Endogenous rate of glucose appearance was calculated by subtracting the exogenous glucose infusion rate from the systemic rate of appearance of glucose. Carbon dioxide incorporation into glucose (as an estimate of gluconeogenesis) was calculated by dividing plasma $\left[{ }^{14} \mathrm{C}\right]$ glucose specific activity by $\left[{ }^{14} \mathrm{C}\right]$ carbon dioxide specific activity and multiplying

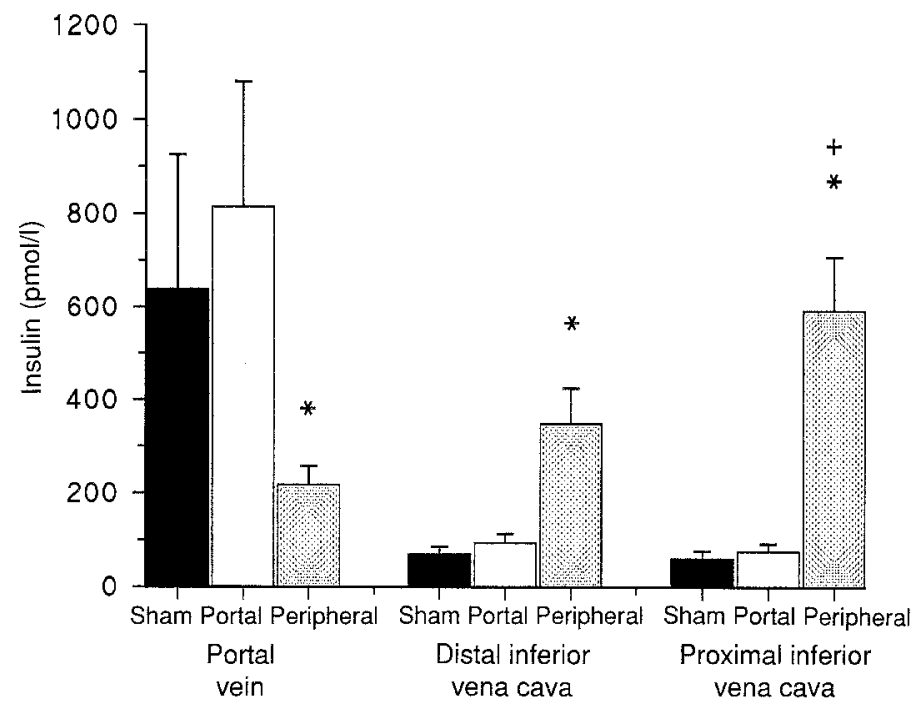

Fig. 1. Insulin concentrations in portal vein, distal inferior vena cava and proximal inferior vena cava $5 \mathrm{~min}$ after peripheral intravenous injection of $10 \mathrm{~g}$ glucose. Sham, $\square$; portal, $\square$; peripheral, 7 . (* $p<0.05$ vs portal group, $+p<0.01$ vs portal vein) 
by the total glucose appearance [16]. Leucine turnover was calculated using both the leucine (i.e., primary-pool model) and ketoisocaproic acid (reciprocal-pool model) atom percent enrichment as previously described [22].

\section{Statistical analysis}

The data in the text and figures are presented as means \pm SEM. To test the hypothesis that peripheral insulin delivery results in insulin resistance, portal and peripheral groups were compared using Student's one-tailed unpaired $t$-tests. Sham and portal groups were compared using Student's two-tailed unpaired $t$-tests to assess changes resulting from surgery alone. Wilcoxon Rank Sum tests for non-parametric data were performed when data did not pass a WilkShapiro test for normality. $p<0.05$ was considered significant.

\section{Results}

\section{Intravenous glucose tolerance test}

Animals in the sham and portal groups had higher $(p<0.05)$ portal than vena cava insulin concentrations 5 min after glucose injection indicating portal drainage of insulin (Fig.1). In contrast, animals in the peripheral groups had higher $(p<0.05)$ insulin concentrations in their proximal vena cava (i.e., proximal to the anastomosis of the pancreaticoduodenal vein to the inferior vena cava) than in either their portal vein or their distal vena cava indicating peripheral insulin drainage. Systemic (i.e., distal vena cava) insulin concentrations were higher $(p<0.02)$ in the peripheral than in the portal group documenting systemic hyperinsulinaemia. In contrast, portal venous insulin concentrations were lower $(p<0.05)$ in the peripheral than portal groups. Although the absolute values were different, the relative relationships of portal and systemic insulin concentrations before and $10 \mathrm{~min}$ after glucose injection were the same in all groups as those observed 5 min after glucose injection (data not shown).

\section{Glucose, insulin, and glucagon concentrations}

Glucose concentrations were equal in the portal, peripheral and sham groups both before and after insulin/glucagon/somatostatin infusion (Fig. 2). Insulin infusion resulted in an increased insulin level from approximately 46 to approximately $175 \mathrm{pmol} / \mathrm{l}$ in all three groups. C-peptide concentrations were equally suppressed in all groups (data not shown). Glucagon concentrations did not differ in the three groups either before or during the final hour of the insulin/glucagon/somatostatin infusion.

\section{Glucose infusion rate, and glucose specific activity}

The glucose infusion rate required to maintain euglycaemia did not differ in the three groups during the first hour of insulin infusion (Fig. 3). Thereafter the glucose infusion rate tended to be lower in the peripheral than portal group with the difference being of borderline significance $(p=0.07)$ during the final hour of the insulin infu-
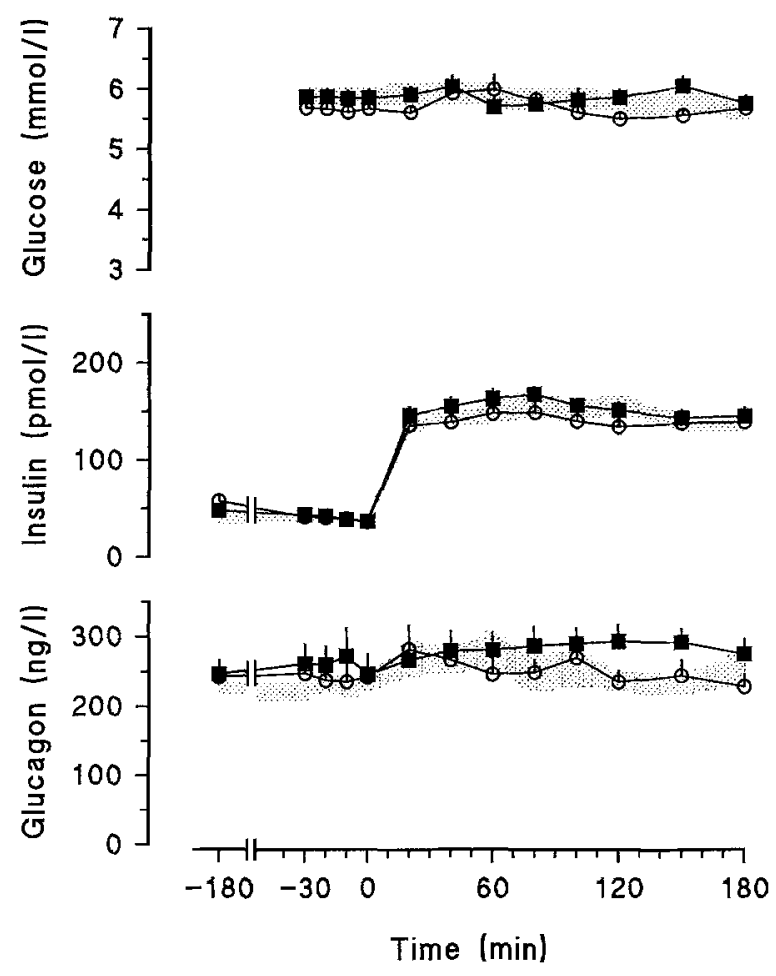

Fig.2. Glucose, insulin and glucagon concentrations at baseline and during hyperinsulinaemic euglycaemic clamp. Insulin infusion was started at time 0 . Portal, $\mathbf{m}$; peripheral, $O$. Shaded areas (sham) are \pm SEM
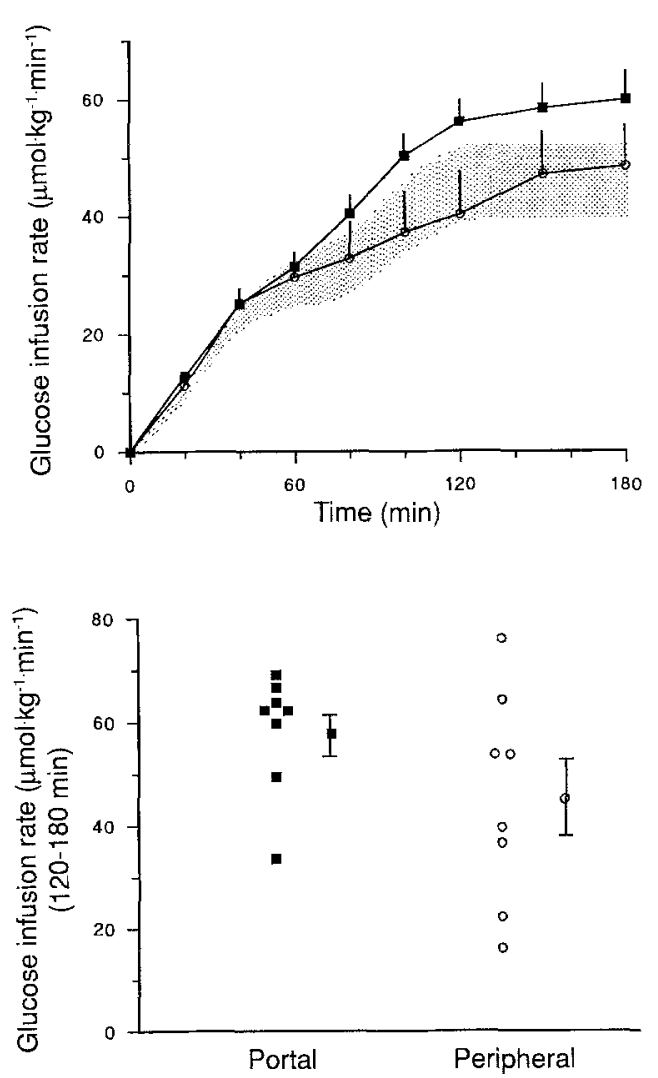

Fig. 3. (Top) Glucose infusion rate required to maintain euglycaemia during hyperinsulinaemic euglycaemic clamp. Portal, $\mathbf{\square}$ peripheral, $O$. Shaded area (sham) is \pm SEM. (Bottom) Scattergram of individual dogs' values for 120-180 min 

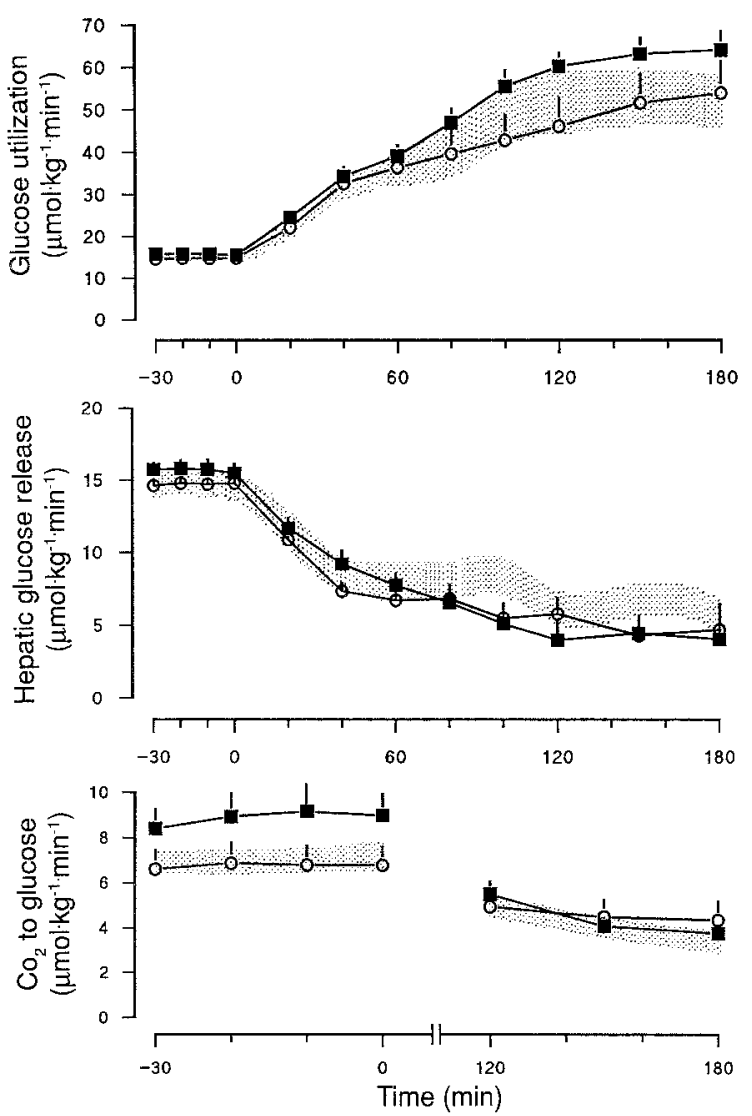

Fig.4. Glucose utilization, hepatic glucose release and estimated carbon dioxide incorporation into glucose at baseline and during hyperinsulinaemic euglycaemic clamp. Insulin infusion was started at time 0 . Portal, $\mathbf{\square}$; peripheral, $\bigcirc$. Shaded areas (sham) are \pm SEM

sion $\left(45 \pm 7\right.$ vs $\left.58 \pm 4 \mu \mathrm{mol} \cdot \mathrm{kg}^{-1} \cdot \mathrm{min}^{-1}\right)$. Somewhat surprisingly, results in the sham group were more similar to those in the peripheral group than those in the portal group. Since the exogenous glucose contained $\left[6-{ }^{3} \mathrm{H}\right]$ glucose at a specific activity equal to that present in plasma, plasma glucose specific activity during the final hour of the insulin infusion did not differ significantly from that present prior to the insulin infusion (data not shown).
Glucose utilization, hepatic glucose release and carbon dioxide incorporation into glucose

The pattern of isotopically-determined glucose utilization closely paralleled that of the glucose infusion (Fig.4), being similar during the first hour but somewhat lower in the peripheral than portal groups during the final hour of the insulin infusion $\left(50 \pm 7 \mathrm{vs} 62 \pm 4 \mu \mathrm{mol} \cdot \mathrm{kg}^{-1} \cdot \mathrm{min}^{-1}\right.$, $p=0.07$ ). Hepatic glucose release did not differ in the portal and peripheral groups either before or during the insulin infusion. Carbon dioxide incorporation into glucose tended to be higher $(p=0.07)$ in the portal than in the peripheral group before but not during insulin infusion. Hepatic glucose release and carbon dioxide incorporation into glucose did not differ in the portal and sham groups either before or during insulin infusion.

\section{Leucine concentrations and turnover}

Leucine and ketoisocaproate concentrations did not differ in the peripheral and portal groups either before or after insulin infusion (Table 1). Leucine turnover also did not differ between groups regardless of whether it was calculated using primary- or reciprocal-pool models. Leucine concentrations and rates of turnover were slightly but not significantly lower in the sham group than those in the portal group.

\section{Palmitate concentration and turnover}

Since the insulin infusion rate employed results in maximal suppression of lipolysis, palmitate concentration and turnover were only measured before insulin infusion. Both were equal in all groups (Table 1).

\section{Discussion}

The present study was undertaken to examine the effects of chronic peripheral insulin delivery and the resultant systemic hyperinsulinaemia on carbohydrate, protein and fat

Table 1. Amino acid and fatty acid concentrations and turnovers

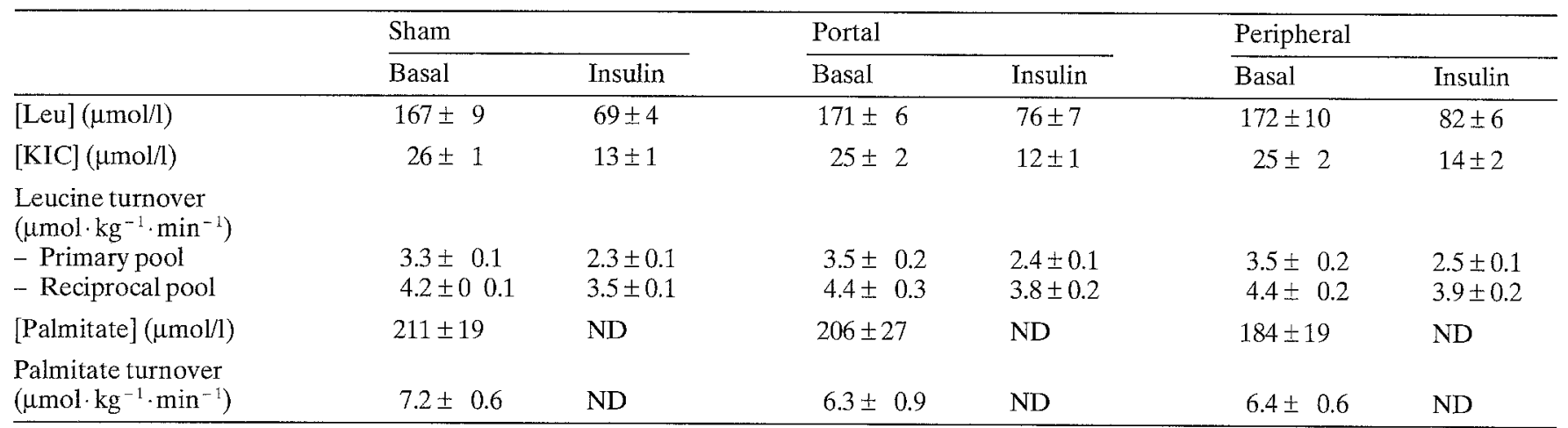

Values obtained prior to ( -30 to $0 \mathrm{~min}$; basal) and during (120 to $180 \mathrm{~min}$ ) insulin infusion. [Leu], leucine concentration; [KIC], ketoisocaproate concentration; [palmitate], palmitate concentration;
ND, not determined. There were no significant differences between groups in any measurements 
metabolism. The surgical model effectively produced systemic delivery of insulin as demonstrated by: 1) a distal to proximal inferior vena cava insulin concentration gradient with equivalent portal vein and distal inferior vena cava insulin concentration in the peripheral group; and 2) equivalent distal and proximal inferior vena cava insulin concentrations with higher portal vein insulin concentrations in the portal and sham groups. Systemic hyperinsulinaemia in the peripheral group was further established by documenting higher distal inferior vena cava insulin concentrations in the peripheral than in the portal group both following an overnight fast and after intravenous glucose. Consistent with previous reports $[5,12]$, these data further document that peripheral diversion of pancreatic venous drainage results in chronic systemic hyperinsulinaemia.

Previous experiments seeking to define the effects of hyperinsulinaemia on insulin action have not always reached concordant conclusions [6-10, 23, 24]. Some studies have suggested that hyperinsulinaemia enhances insulin action [23-25], whereas other studies have suggested that hyperinsulinaemia either decreases or has no effect on tissue response to insulin $[6-9,26]$. These discrepant observations may be due in part to differences in glucose and counterregulatory hormone concentrations present during insulin administration, modes of insulin infusion (continuous vs pulsatile), tissues studied, and methods of assessing insulin action. The present study sought to avoid these limitations. The pancreas remained in situ and innervated; euglycaemia was maintained; insulin was secreted in a physiologic pattern; hepatic and extrahepatic responses were assessed; and insulin effects on protein and NEFA as well as glucose metabolism were evaluated.

In the present experiments, glucose utilization during a hyperinsulinaemic euglycaemic clamp was slightly lower in the peripheral insulin delivery group than in the portal group. Even then, the differences were small, variable and did not become apparent until after $1 \mathrm{~h}$ of insulin infusion. The minimal impairment in insulin action was only evident when an approach (one-tailed Student's test) designed to maximize the possibility of detecting a difference if it existed was used for statistical analysis. Furthermore, since under daily living conditions (e.g., after meal ingestion) the rate of onset of insulin action is likely to be as, if not more important than the eventual steady-state response to a given insulin concentration [2730], a slight decrease in glucose uptake after several hours of insulin infusion may have little or no impact on carbohydrate tolerance. These data suggest that hyperinsulinaemia associated with systemic insulin delivery causes only a mild impairment in the ability of insulin to stimulate glucose uptake. The physiologic significance, if any, of this mild impairment remains to be determined.

In contrast to glucose uptake, hepatic glucose release was equal in all groups both before and during insulin infusion. Thus, there was no suggestion that the chronic portal hypoinsulinaemia present in the peripheral group resulted in increased hepatic insulin sensitivity. Similarly, no differences were found between groups in the estimated rate of incorporation of carbon dioxide into glucose (a qualitative index of gluconeogenesis) during hyperinsulinaemia. However, the estimated rate of car- bon dioxide incorporation into glucose prior to the insulin infusion was higher in the portal than in the peripheral group, suggesting increased rates of gluconeogenesis. We have previously reported a similar observation in a separate group of dogs subjected to identical surgical procedure [12]. The limitations of the use of the rate of carbon dioxide incorporation into glucose to assess gluconeogenesis have been previously discussed [16, 31, 32].

At least in theory, a decreased rate of gluconeogenesis could result from decreased availability of gluconeogenic substrate and/or decreased gluconeogenic efficiency. The present study demonstrates that both the basal rate of proteolysis (as reflected by leucine appearance into the systemic circulation) and the decrement in proteolysis in response to insulin were similar regardless of whether the pancreas venous effluent was drained into the systemic circulation or into the portal venous circulation.

Non-esterified fatty acids could also influence gluconeogenic efficiency by altering the availability of both energy and reducing equivalents. However, as with leucine, fatty acid turnover was equal in the portal and peripheral groups. Palmitate turnover was assessed only in the basal state because prior studies have shown that the insulin concentrations present during the insulin infusion would result in marked suppression of lipolysis in all groups [33]. Thus, we find no evidence that chronic systemic insulin delivery alters either proteolysis or lipolysis. Further studies will be required to determine whether peripheral hyperinsulinaemia alters intrahepatic metabolism and/or supply of other gluconeogenic precursors.

In order to maximize our chances of detecting a difference between systemic and portal insulin delivery, we simultaneously measured insulin concentrations in the portal vein and inferior vena cava before and after intravenous glucose. We developed prospective criteria for excluding any animal in which the route of drainage was not clear. Using these criteria, eight of the initial $33 \mathrm{dogs}$ were excluded. Because these eight dogs presumably developed enough collateral circulation to make their route of pancreatic venous drainage ambiguous, it is reasonable to assume that a lesser degree of collateralization may have been present in the remaining dogs. Thus, we cannot exclude the possibility that more marked metabolic differences may have been detected in animals with exclusively peripheral or portal insulin drainage. However, it is probable that collateralization between the pancreas and the mesentery also develops after human pancreas transplantation.

In order to ensure that all venous drainage is via the pancreaticoduodenal vein, the remaining venous drainage must be interrupted. This results in venous congestion and loss of portions of the pancreas. We therefore also compared results observed in the portal group to those observed in a sham-operated group to evaluate the effects of the operative procedure including partial pancreatectomy. Although no significant differences were found in any of the parameters measured between groups, glucose uptake during insulin infusion tended to be higher in the portal than in the sham animals implying enhanced insulin action in the former. This intriguing result is consistent with several recent reports that a decrease in Beta-cell 
mass either via pancreatic resection [34] or by administration of streptozotocin [35] may be associated with an increase in insulin action. Partial pancreatectomy could also have altered the response in the peripherally drained group if, by reducing the mass of Beta cells, it impaired insulin secretion. In previous experiments we found no evidence of decreased insulin secretion since C-peptide response to a mixed meal was similar in the peripheral and sham groups [12].

It is possible that the severity of insulin resistance might have been greater if the duration of hyperinsulinaemia had been longer than $8-10$ weeks. This concern is particularly pertinent to human pancreas transplantation where hyperinsulinaemia may be present for the duration of the recipient's life. Both in vitro and in vivo studies have demonstrated that insulin action can be rapidly modulated by insulin $[6-10,23,24]$. In the only study to our knowledge that has examined the effects of duration of hyperinsulinaemia on insulin action, Wardzala et al. reported a transient increase in adipocyte and muscle response to insulin after 2 weeks of hyperinsulinaemia which was subsequently lost in muscle after 6 weeks of hyperinsulinaemia [8]. Whereas the possibility remains that the defect in insulin-stimulated glucose uptake noted in the present study may have become more severe with increasing duration of hyperinsulinaemia, we believe it is unlikely that an impairment in insulin-induced suppression of hepatic glucose release, lipolysis and/or proteolysis would subsequently become evident, since there was no hint of a defect at the time of study. However it should be noted that the present animals were studied in the fasted state when insulin concentrations in the peripheral group approached those in the portal group. Insulin resistance might be more marked in the peripheral group in the fed state when hyperinsulinaemia is greatest.

Future metabolic deterioration due to Beta-cell exhaustion would not be anticipated since previous studies have demonstrated that systemic hyperinsulinaemia associated with peripheral insulin delivery is due to decreased hepatic insulin clearance rather than increased insulin secretion $[2-4,12]$. The impairment in insulin action is minimal and appears to be restricted to glucose uptake in peripheral tissues without altering the rates of either proteolysis or lipolysis. The present results, taken together with the recent reports by Luzi et al. $[36,37]$ documenting that glucose uptake and leucine turnover during a hyperinsulinaemic euglycaemic clamp did not differ in diabetic patients who had received combined pancreaskidney transplants from patients receiving comparable immunosuppressive therapy, suggest that systemic insulin delivery in itself may not have a major effect on glucose, protein and fat metabolism. On the other hand Falholt et. al. [38] have recently reported that aortic lipid deposition was greater following transplantation of a systemically drained pancreatic autograft than that observed when pancreatic islets were injected into the portal vien. In view of this observation, although systemic hyperinsulinaemia appears to have minimal effects on insulin action, it remains to be determined whether it has other more insidious effects in humans such as altering the risk of atherosclerosis.
Acknowledgements. We wish to thank Ms. J.Aikens, Mr. P.Berg, Ms. J. King, Mr. T.Madson, Ms. D.Nash, Ms. M.Persson, Ms. M. Oeltjen, and D. White for their technical assistance and Ms. J. Ashenmacher for assistance in typing the manuscript. We also wish to thank Dr. K. Polonsky for kindly measuring C-peptide concentrations. This work was supported by grants of United States Public Health Service DK29953, DK38092, DK26989, and DK40484.

\section{References}

1. Pozza G, Bosi E, Secchi A, Piatti P, Touraine J, Gelet A, Pontiroli A, Dubernard JM, Traeger J (1985) Metabolic control of type I (insulin dependent) diabetes after pancreas transplantation. Br Med J 291: 510-513

2. Ostman J, Bolinder J, Gunnarsson R, Brattstrom C, Tyden G, Wahren J, Groth C (1989) Effects of pancreas transplantation on metabolic and hormonal profiles in IDDM patients. Diabetes 38 : 88-92

3. Diem P, Abid M, Redmond J, Sutherland D, Robertson P (1990) System venous drainage of pancreas allografts as independent causes of hyperinsulinaemia in type $I$ diabetic recipients. Diabetes 39: 534-540

4. Osei K, Henry M, O'Dorisio T, Tesi R, Sommer B, Ferguson R (1990) Physiological and pharmacological stimulation of pancreatic islet hormone secretion in type I diabetic pancreas allograft recipients. Diabetes 39: 1235-1242

5. Van Der Burg M, Gooszen H, Guicherit O, Jansen J, Frölich M, Van Haastert F, Lamers C (1989) Contribution of partial pancreatectomy, systemic hormone delivery, and duct obliteration to glucose regulation in canine pancreas. Diabetes 38: 1082-1089

6. Gavin J, Roth J, Neville D, De Meyts P, Buell D (1974) Insulin dependent regulation of insulin receptor concentrations - A direct demonstration in cell culture. Proc Natl Acad Sci USA 71: 8488

7. Marshall S, Olefsky J (1980) Effects of insulin incubation on insulin binding, glucose transport, and insulin degradation by isolated rat adipocytes. $J$ Clin Invest 66: 763-772

8. Wardzala L, Hirshman M, Potcher E, Horton E, Mead P, Cushman S, Horton E (1985) Regulation of glucose utilization in adipose cells and muscle after long-term experimental hyperinsulinaemia in rats. J Clin Invest 76: 460-469

9. Rizza R, Mandarino LJ, Genest J, Baker BA, Gerich JE (1985) Production of insulin resistance by hyperinsulinaemia in man. Diabetologia 28: 70-75

10. Marangou A, Weber K, Boston R, Aitken P, Heggie J, Kirsner R, Best J, Alford F (1986) Metabolic consequences of prolonged hyperinsulinaemia in humans: evidence for induction of insulin insensitivity. Diabetes 35: 1383-1389

11. Horwitz D, Starr J, Mako M, Blackard W, Rubenstein A (1975) Proinsulin, insulin and C-peptide concentrations in human portal and peripheral blood. J Clin Invest 55: 1278 1283

12. Kryshak E, Butler P, Marsh C, Miller A, Barr D, Polonsky K, Perkins J, Rizza R (1990) Pattern of postprandial carbohydrate metabolism and effects of portal and peripheral insulin delivery. Diabetes 39: 142-148

13. Barr D, Miller A, Marsh C, Kryshak E, Butler P, Rizza R, Perkins J (1990) Diversion of the gastroduodenal vein: a canine model for comparing portal versus systemic insulin delivery. Transplant Proc 22: 702-703

14. Herbert V, Lau K, Gottlieb C, Bleicher S (1965) Coated charcoal immunoassay of insulin. J Clin Endocrinol Metab 25: 13751384

15. Faloona G, Unger R (1974) Glucagon. In: Jaffe B, Behrman H (eds) Methods of hormone radioimmunoassay. Academic Press, New York, pp 317-330

16. McMahon M, Marsh M, Rizza R (1989) Effects of basal insulin supplementation on the disposition of a mixed meal in obese patients with non-insulin dependent diabetes. Diabetes 38: 291303 
17. Firth R, Bell P, Marsh H, Hansel I, Rizza R (1986) Postprandial hyperglycemia in patients with noninsulin-dependent diabetes mellitus. J Clin Invest 77: 1525-1532

18. Miles J, Ellman M, McClean K, Jensen M (1987) Validation of a new method for determination of free fatty acid turnover. Am J Physiol 252: E431-E438

19. Jensen M, Rogers P, Ellman M, Miles J (1988) Choice of infusion-sampling mode for tracer studies of free fatty acid metabolism. Am J Physiol (Endocrinol Metab) 254: E562-E565

20. Haymond M, Howard C, Miles J, Gerich J (1980) Determination of leucine flux in vivo by gas chromatography-mass spectrometry utilizing stable isotopes for trace and internal standards. J Chromatogr 183: 403-409

21. Steele R, Wall J, De Bodo R, Altszuler N (1956) Measurement size and turnover rate of body glucose pool by the isotope dilution method. Am J Physiol 187: 15-24

22. Schwenk W, Beaufrere B, Haymond M (1985) Use of reciprocal pool specific activities to model leucine metabolism in humans. Am J Physiol 249 (Endocrinol Metab 12): E646-E650

23. Kobayashi M, Olefsky JM (1979) Effect of experimental hyperinsulinaemia on intracellular glucose metabolism of isolated adipocytes. Diabetologia 17: 111-116

24. Trimble E, Weir G, Gjinovci A, Assimacopoulos-Jeannet F, Benzi R, Renold A (1984) Increased insulin responsiveness in vivo and in vitro consequent to induced hyperinsulinaemia in the rat. Diabetes 33: 444-449

25. Ward G, Walters J, Aitken P, Best J, Alford F (1990) Effects of prolonged pulsatile hyperinsulinaemia in humans. Diabetes 39: 501-507

26. Beylot M, Khalfallah Y, Laville M, Sautot G, Dechaud H, Serusclat P, Berthezene F, Riou JP, Mornex R (1987) Insulin-mediated glucose disposal in Type 1 (insulin-dependent) diabetic subjects treated by continuous subcutaneous or intraperitoneal insulin fusion. Diabet Metab 13: 450-456

27. Bratusch-Marrain P, Waldhäusl W (1985) Impact of the "early peak" of insulin secretion on glucose utilization in man. Horm Metabol Res 17: 163-164

28. Doeden B, Rizza R (1987) Use of a variable insulin infusion to assess insulin action in obesity: Defects in both the kinetics and amplitude of response. J Clin Endocrinol Metab 64: 902-908

29. Prager R, Wallace P, Olefsky J (1986) In vivo kinetics of insulin action on peripheral glucose disposal and hepatic glucose output in normal and obese subjects. J Clin Invest 78: 472-481
30. Bruce D, Chisholm D, Storlien L, Kraegen E (1988) Physiological importance of deficiency in early prandial insulin secretion in non-insulin-dependent diabetes. Diabetes 37: 736-744

31. Katz J (1985) Determination of gluconeogenesis in vivo with ${ }^{14} \mathrm{C}$-labelled substrates. Am J Physiol 17: R391-R399

32. Brosnan J (1982) Pathways of carbon flux in gluconeogenesis. Fed Proc 41: 91-95

33. Jensen M, Caruso M, Heiling V, Miles J (1989) Insulin regulation of lipolysis in nondiabetic and IDDM subjects. Diabetes 38 : 1595-1601

34. Kendall D, Sutherland D, Najarian J, Goetz F, Robertson R (1990) Effects of hemipancreatectomy on insulin secretion and glucose tolerance in healthy humans. N Engl J Med 322: 898-903

35. Kergoat M, Guerre-Millo M, Lavau M, Portha B (1991) Increased insulin action in rats with mild insulin deficiency induced by neonatal streptozotocin. Am J Physiol (Endocrinol Metab 23) 260: E561-E567

36. Luzi L, Secchi A, Facchini F, Battezzati A, Staudacher C, Spotti D, Castoldi R, Ferrari G, Di Carlo V, Pozza G (1990) Reduction of insulin resistance by combined kidney-pancreas transplantation in Type 1 (insulin-dependent) diabetic patients. Diabetologia 33:549-556

37. Luzi L, Battezzati A, Carpinelli A, Facchini F, Secchi A, Spotti D, Di Carlo V (1990) Leucine metabolism in insulin-dependent diabetic uremic patients (IDDUP): effect of isolated kidney (K-Tx) and combined kidney-pancreas (KP-Tx) transplantation. Diabetes 39: 117A

38. Falholt K, Cutfield R, Alejandro R, Vølund A, Heding LG, Mintz DH (1991) Influence of portal delivery of insulin on intracellular glucose and lipid metabolism. Metabolism 40: 122-126

Received: 12 March 1991

and in revised form: 17 June 1991

Dr. R. Rizza

Mayo Clinic

Rochester, MN 55905

USA 